It is with this in mind that Gilpin calls for managers to become more "hypothesis conscious" in their dealings with the communities in their charge. He also calls for the pooling of data - precisely as is done by physicians to help make up for the inadequacies presented by data gathered in the course of efforts undertaken for other reasons.

Both of these seem to us to be intriguing suggestions, and we hope to hear more of them in the future.

\section{Summing Up Volume I}

When we sent out the first issue of Restoration and Management Notes two years ago, we had no idea what would come of it. We thought there was a need for better communication in this area; we thought we had put together a first issue that represented fairly well what we could do to encourage that communication; and we had compiled a good list of prospective readers. That first, complimentary issue was mailed to some 2400 persons all over the country. It made an impressive pile in the back of the arboretum van. But we had no idea how many of those receiving it would read it, or how many, having read it, would want to see another copy.

Now as we mail off this fourth and final issue of Volume I, we are happy to report that a great many of those persons did want to see more. The response to R\&MN has exceeded our expectations severalfold; we now have more than 1,400 subscribers - an impressive number for a young publication without a ready-made audience, and with limited resources for promotion.

The point is that R\&MN is working, and it is working because our readers are enthusiastic about it. They read it - some of them apparently with a fine-toothed comb. They write us about it, and they tell others about it. And that's great because our subscribers are also contributors. The more of them we have the more valuable Notes will be, the more it will contain, the more persons it will put you in touch with; and, not insignificantly, the more economically we can produce it.

Last winter we included a reader reply card in the third issue, hoping to get some advice on a few questions that keep coming up. We think some of the answers are worth passing on.

In general, readers who responded seemed to like what we are doing. Most of them indicated they read more than half of each issue, and many wrote they read 90 or 100 percent. In the same vein, there was little interest in cutting anything out, though there were a few comments on notes from the southeast or the west-areas not included in our region, defined, tentatively, along ecologi$\mathrm{cal}$ lines to include the forests, prairies and wetlands of the eastern United States. So far we have stuck to this, but only loosely, and we have accepted contributions from farther afield if we felt they would interest our midwestern and eastern readers. There has been real interest in having R\&MN expand to include the entire United States, or all of North America. In particular we have heard from persons in Florida and California, both areas where restoration and management seem to be especially vigorous enterprises. And in a review in the winter issue of CoEvolution Quarterly, Peter Warshall described R\&MN as ". . . a great success," that "... should be copied in every other bioregion of the planet." Obviously this is something we will be considering, and, as usual, opinions are welcome.

As to subjects, our respondents like what's there and would like to see more of the same. They call for more of everything - from the nitty-gritty of propagation and pest control to history and philosophy. Readers clearly like the style and format-especially the preponderance of short notes with names and addresses. Bonnie Harper of Northfield, Minnesota was kind enough to report that "I read with interest more pages of R\&MN than the rest of my professional periodicals combined." Still the inclusion of a few longer articles in each issue has generally been welcome, with a majority of readers reporting they'd like to see more of them.

As to the metric system - that also fared surprisingly well. Forty percent of our respondents are happy with the metric system alone. Another third would like to see both metric and English units used together. Only a few urged English only. For the moment we are following a course somewhere midway-metric system, with occasional exceptions as appropriate, and with a conversion table inside the front cover - a suggestion made by several readers.

We also picked up a lot of ideas from the reply cards, some of which we'll be following up on. One, from Mark Heitlinger at The Nature Conservancy, was for the comprehensive index, which we have included at the back of this issue.

Keep in touch! 